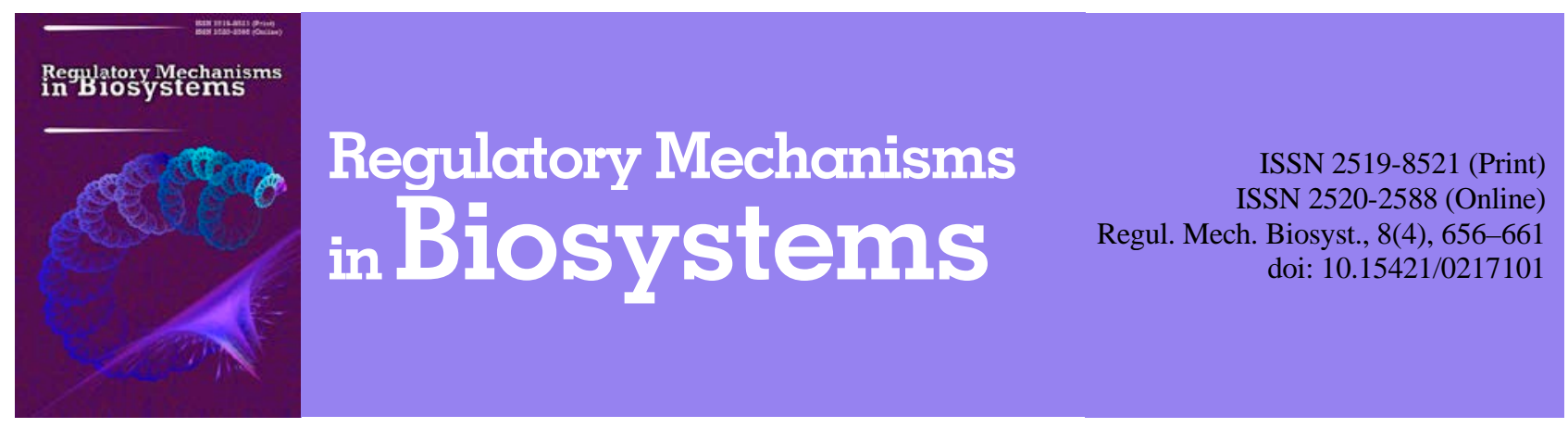

\title{
Ethnobotanical and ecological study of Punica granatum in Dir district, Khyber Pakhtunkhwa, Pakistan
}

\author{
K. Ali*, S. Khan*, N. Khan*, W. Khan**, I. U. Rahman*, F. Ullah*, K. Ali***, M. Nisar* \\ *University of Malakand, Chakdara, Pakistan \\ **Nanjing Agricultural University, Nanjing, China \\ ***University of Swat, Khyber Pakhtunkhwa, Pakistan
}

\section{Article info}

Received 16.10.2017

Received in revised form 12.11.2017

Accepted 15.11.2017

University of Malakand, Chakdara, Dir lower, Khyber Pakhtunkhwa, Pakistan. E-mail:kishwarali@live.com waqar.khan399@gmail.com

Nanjing Agricultural University, Nanjing, 210095, China.

Centre of Biotechnology and Microbiology, University of Swat, Khyber Pakhtunkhwa, Pakistan.

\section{Introduction}

Pomegranate (Punica granatum L.) is a plant beloved from ancient times. The utilization of the pomegranate can be traced to the ancient human cultures such as Greeks and Romans as a food and for various medical remedies. The uses of $P$. granatum are deeply embedded in human history. The pomegranate tree requires a hot, dry and long season to get a good and large quality of fruits (Morton, 1887).

The family Punicaceae is mono-generic, with only two species. P. protopunica Lucas and Synge, 1978 is confined to the island of Socotra only. The members of this family originated mainly in Iran and then spread widely in ancient times to the Himalayas and the Mediterranean region of Europe. In Iran, Pakistan, India, Egypt, Afghanistan, Iraq, China, Bangladesh, Saudi Arabia and Burma P. granatum grows well (Morton, 1987). It is believed that from its point of origin in the Middle East, it spread first to the Mediterranean region, India and China, and later to America, Mexico and California (Robert et al., 2002). The plant has native and well-defined forest patches in the northern areas of Pakistan. The plant is commonly found at altitudes of 1000 $2000 \mathrm{~m}$ in the north-west of Pakistan but the wild pomegranate is frequently grown especially in Khyber Pakhtunkhwa (Chitral, Dir and Kurrum), Baluchistan and south-Waziristan the. It is also found in some areas of Kashmir and Hazara (Kotmballi et al., 2002; Jurenka, 2008; Ali et al., 2015). The present study was undertaken in Lower Dir District, Khyber Pakhtunkhwa, Pakistan (Fig. 1), to identify the main reasons for plant communities, as well as geo-referenced data of the species in the study area (Fig. 2). The total area of Lower Dir is $1,583 \mathrm{~km}^{2}$ and lies in the Lesser Hindu Kush range between $35^{\circ} 10^{\prime}$ to $35^{\circ} 16^{\prime} \mathrm{N}$ Latitude and $71^{\circ} 50^{\prime}$ to $71^{\circ} 83^{\prime} \mathrm{E}$ Longitudes (Khan et al., 2010) with three major temperature variation zones (Fig. 3).

Due to overexploitation of the plants for various reasons it is very close to being lost from their natural habitat.

\section{Material and Methods}

Data collection. Frequent field trips were made to evaluate the species status from the residents of Lower Dir. The respondents were divided into four groups based on their ages. The total number of respondents was 124; 24 of whom were 20 to 30 years old, 30 were 31 to 40 years old, 28 were 41 to 50 years old and 42 were aged 51 and above (Table 1). All the respondents were local inhabitants of Lower Dir district. The interviews were conducted in the local language Pashto. The key questions included in the interviews were about the folk uses of the plant, recipes, its ecological structure and reason for extinction and/or survival.

Relative Frequency of Citation (RFC). The collected ethno-medicinal data was quantitatively analysed using the Relative Frequency of Citation (RFC) index. This indicator shows the local importance of the species and is calculated from the frequency of citation (FC, the number 
of informants mentioning the usage of the species) divided by the total number of informants in the survey $(\mathrm{N})$, without considering the use categories (Ahmad et al., 2014) using the formula:

$$
\mathrm{RFC}=\mathrm{FC} / \mathrm{N} \text {, }
$$

value ranges from zero (none of the informants cited the plant as useful) to one (every informant reported the plant to be useful (Sadeghi and Kuhestani, 2014)).

Use value (UV). The use value (UV) demonstrates the relative importance of locally known plants (Rawat et al., 2010). It is calculated using the formula:

$$
\mathrm{UV}=\sum \mathrm{U}_{\mathrm{i}} / \mathrm{N},
$$

where $U_{i}$ is the number of uses mentioned by each information for a given species and $\mathrm{N}$ is the total number of informants.

Geo-referenced data on the species sites. Georeferenced data on the species was collected from the study area, using GPS. The collected degree, minute and second format was converted into decimal point format by the formula

$$
\left(\mathrm{C}_{2}+\mathrm{D}_{2} / 60\right)+\left(\mathrm{E}_{2} / 3600\right) \text { and }\left(\mathrm{F}_{3}+\mathrm{G}_{3} / 60\right)+\left(\mathrm{H}_{3} / 3600\right) \text {. }
$$

The spreadsheets were converted to CSV comma delimited format and inserted to GIS for the development of thematic maps (Fig. 2).

Cluster analysis. Plant communities in various parts of the district were assessed on the basis of their similarities and differences. Cluster analysis function of PC-ORD with two-way cluster analysis method was applied using distance measure (correlation) and group linkage method (Ward's method).

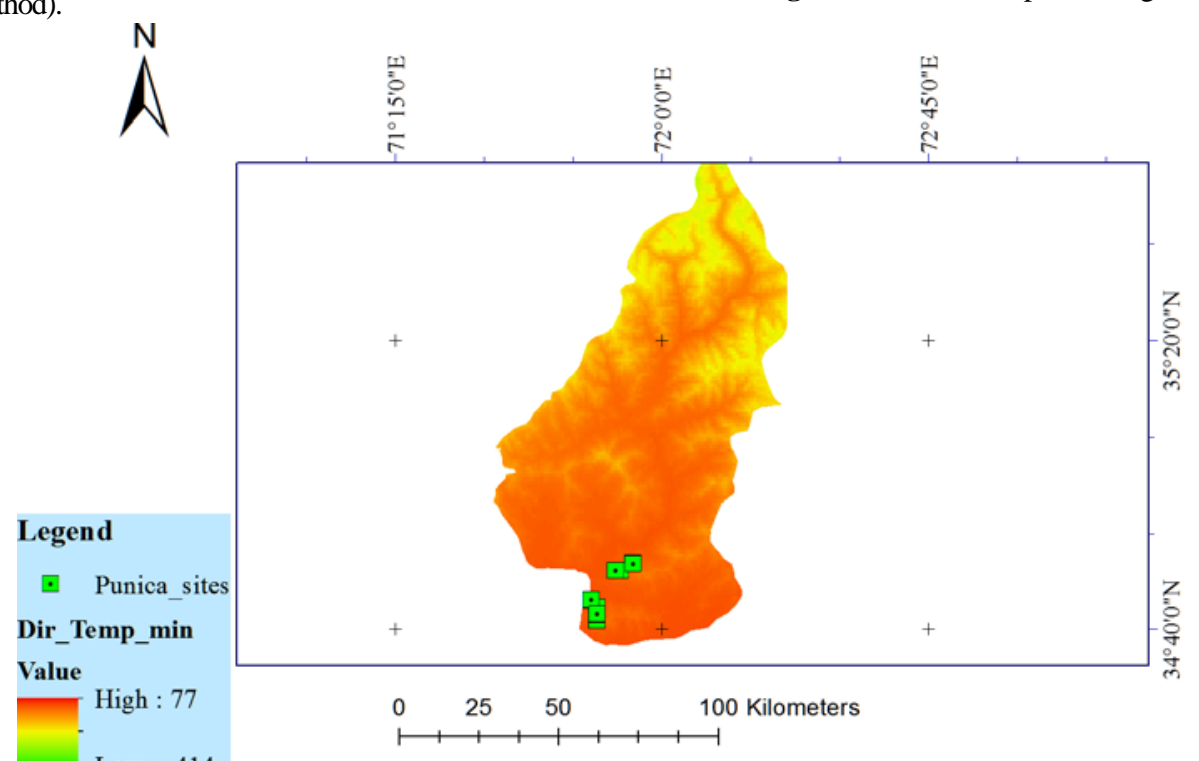

Fig. 2. Punica granatum sites assessed during the field work

\section{Results}

Folk uses of $\boldsymbol{P}$. granatum. Residents' perspectives about this plant evaluated in this category of results were very interesting. The responses of the people about the medicinal uses of $P$. granatum are summarized (Table 1). In the common domain, the plant was used for the treatment of dry cough, urine irritation, stomach disease, diarrhoea, bone pain, chest pain, skin irritation, dysentery and throat infection. People use this plant as refrigerant, anti-diabetic, anthelmintic, expectorant, astringent and as a blood purifier. About $18.0 \%$ of people used it for treating dry cough, $17.0 \%$ people used it for urine irritation and for stomach disorders. Just over 9.0\% used it for diarrhoea, 7.0\% used it for blood purification, $6.0 \%$ for arthritis related issues, and chest pain. Skin irritation and refrigerant use was restricted to only $4.7 \%$ of people of the area. About $4.0 \%$ used it for dysentery, 3.1\% of people used it as anti-diabetic, $2.3 \%$ of people used it as an anthelmintic, $2.3 \%$ of people used it for throat infection, $1.6 \%$ of people used it as an expectorant and $1.8 \%$ of people used it as an astringent.

Recipes with $P$. granatum. It is evident from the results that only 10 recipes are in common use in the study area for $P$. granatum. Most of the inhabitants (27.6\%) used the powder form of the plants, $26.2 \%$

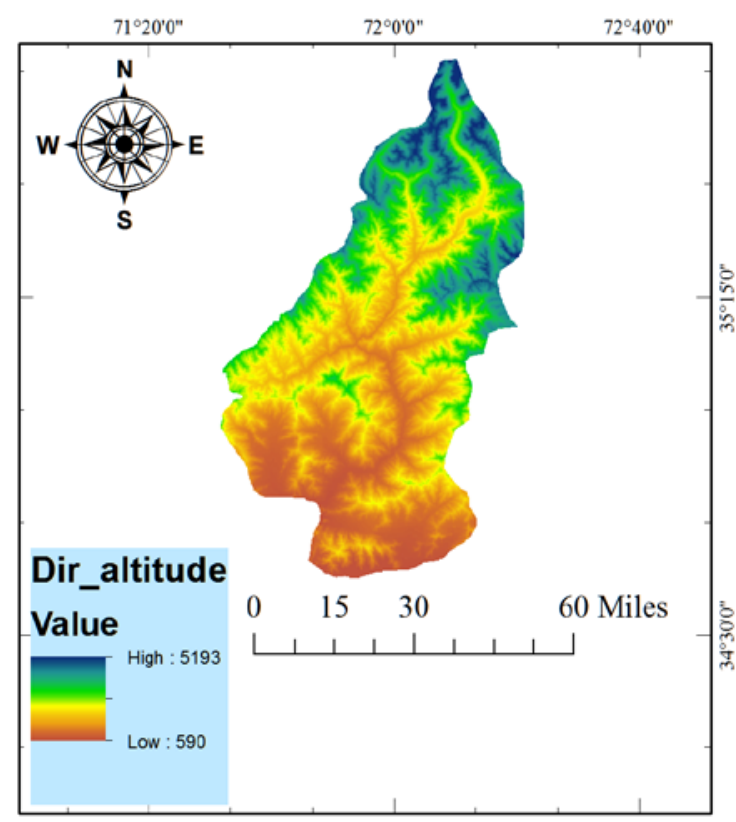

Fig. 1. Dir District map with its geocoordinates mixed the powder with water, $17.2 \%$ mixed it with sugar, $10.3 \%$ of people used the seeds as food, $2.8 \%$ used the powder form of the drug mixed with opium, $2.1 \%$ used seeds mixed with vegetables, $1.4 \%$ of people used fresh extract of juice from the seeds, $2.8 \%$ used the powder form mixed with other sweets. Some people, $4.1 \%$, used the fruits' peels as medicine (Table 2).

Conservation indicators of $\boldsymbol{P}$. granatum. Responses to the question about the survival of the species suggest that over $18.0 \%$ of the respondents agree that the plant has survived due to its inaccessibility to humans, $13.0 \%$ people relate it to steep slopes, while $13.2 \%$ of people says that this plant has survived due to its chance appearance on fertile soil. People's perception suggests that $13.2 \%$ of people believe that there is a connection between the plant's ability to absorb water efficiently. Some $11.4 \%$ suggest that it has survived due to the spines growing on the plants, others, just over $10.0 \%$ link it to the secondary growth system. Some $8.0 \%$ people suggest that these plants have survived due to their medicinal value. Other insignificant reasons were also mentioned (Table 3).

Eradication indicator of $\boldsymbol{P}$. granatum. In the present study, reasons for the serious decline of $P$. granatum in the study area were also investigated. The most important reason for its decline recorded was its overuse as firewood. Other reasons include ease of human access to the 
plant, excessive use of its fruits, high palatability, soil erosion, overuse of the seeds, lack of official protection status, occurrence in sites unsuitable for growth, vulnerability to water logging and salinity etc. (Table 4). The agreement percentage is $17.1 \%$ who believe that its decline is due to its overuse as firewood, $15.5 \%$ of people say that the main reason for its de- cline is due to its accessibility to humans, $14.0 \%$ of people say that the main reason for its decline is excessive use of fruits and high palatability, $12.4 \%$ of respondents say that the main reason for its loss is due to soil erosion. Some people also relate the loss of the species to climatic changes in the area.

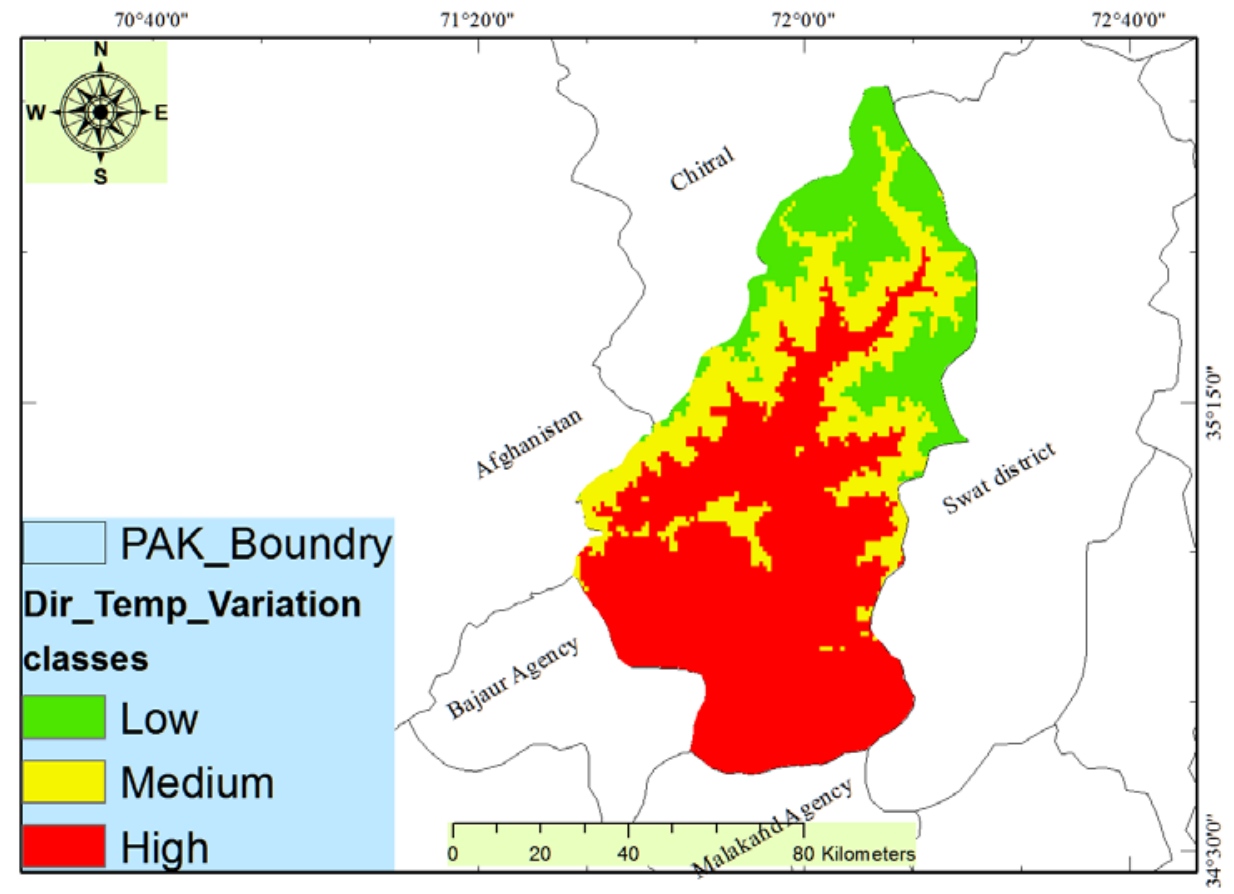

Fig. 3. Temperature variation in Dir District

Table 1

Medicinal folk uses of Punica granatum plant in Lower Dir District, KP, Pakistan

\begin{tabular}{|c|c|c|c|c|c|c|c|c|}
\hline Folk uses (Dir L) KP & FC (20-30) & FC (31-40) & FC (41-50) & FC (51-above) & $\sum \mathrm{U}_{\mathrm{i}}$ & $\mathrm{N}$ & Use value (UV) & $\%$, UV \\
\hline Dry cough & 3 & 7 & 5 & 8 & 23 & 128 & 0.179 & 17.96 \\
\hline Urine irritation & 3 & 4 & 7 & 8 & 22 & 128 & 0.171 & 17.18 \\
\hline Stomach disease & 4 & 3 & 3 & 5 & 15 & 128 & 0.117 & 17.71 \\
\hline Diarrhoea & 2 & 5 & 2 & 3 & 12 & 128 & 0.093 & 9.37 \\
\hline Blood purification & 1 & 2 & 3 & 4 & 10 & 128 & 0.078 & 7.81 \\
\hline Bone pain & 1 & 3 & 1 & 3 & 8 & 128 & 0.062 & 6.25 \\
\hline Chest pain & 1 & 2 & 3 & 2 & 8 & 128 & 0.062 & 6.25 \\
\hline Skin irritation & 2 & 2 & 0 & 2 & 6 & 128 & 0.046 & 4.68 \\
\hline Refrigerant & 1 & 2 & 1 & 2 & 6 & 128 & 0.046 & 4.68 \\
\hline Dysentery & 1 & 1 & 2 & 1 & 5 & 128 & 0.039 & 3.90 \\
\hline Anti-diabetic & 1 & 2 & 1 & 0 & 4 & 128 & 0.031 & 3.12 \\
\hline Anthelmintic & 1 & 1 & 0 & 1 & 3 & 128 & 0.023 & 2.34 \\
\hline Throat infection & 0 & 1 & 1 & 1 & 3 & 128 & 0.023 & 2.34 \\
\hline As expectorant & 0 & 1 & 0 & 1 & 2 & 128 & 0.015 & 2.34 \\
\hline Astringent & 0 & 0 & 0 & 1 & 1 & 128 & 0.007 & 1.78 \\
\hline
\end{tabular}

Note: FC - frequency of citation, $\Sigma$ Uri - the total number of uses mentioned by each informant, $\mathrm{N}$ - the total number of informants, UV - use value, \%UV the percentage of use value.

Table 2

Use value of different recipes with Punica granatum for curing different diseases in Lower Dir District, KP, Pakistan

\begin{tabular}{|c|c|c|c|c|c|c|c|c|}
\hline Recipes (Dir L) KP & FC (20-30) & FC $(31-40)$ & FC (41-50) & FC (51-above) & $\sum \mathrm{Ui}$ & $\mathrm{N}$ & Use value (UV) & \%UV \\
\hline Powder form is used & 9 & 10 & 10 & 11 & 40 & 145 & 0.27 & 27.58 \\
\hline Powder form is mixed with water & 6 & 11 & 10 & 11 & 38 & 145 & 0.26 & 26.20 \\
\hline Powder form is mixed with sugar & 3 & 5 & 9 & 6 & 25 & 145 & 0.17 & 17.24 \\
\hline Seed is used as a food & 2 & 3 & 2 & 8 & 15 & 145 & 0.10 & 10.34 \\
\hline Powder form is mixed with opium & 1 & 1 & 0 & 2 & 4 & 145 & 0.02 & 2.75 \\
\hline Powder form is mixed with milk & 1 & 3 & 0 & 4 & 8 & 145 & 0.05 & 5.51 \\
\hline Seed is mixed with vegetables & 2 & 0 & 0 & 1 & 3 & 145 & 0.02 & 2.06 \\
\hline Extraction of juice from seed & 0 & 1 & 0 & 1 & 2 & 145 & 0.01 & 1.37 \\
\hline Powder form is mixed with other sweets & 2 & 1 & 1 & 0 & 4 & 145 & 0.02 & 2.75 \\
\hline Small part of fruit bark is used & 1 & 0 & 2 & 3 & 6 & 145 & 0.04 & 4.13 \\
\hline
\end{tabular}

\section{Note: see Table 1.}

Cluster analysis. The various plant communities of the area were also tested for their similarities and differences. It is clear from the cluster diagram based on the habitat of the various stands that some stands show similarities in their habitat (Fig. 4). The data was recoded from five types of habitats i.e. plain, streams, farmlands, steep slopes and springs. From the cluster diagram, it is evident that, St.1, St.2, 
St.3, St.4, St.10, St.14, St.17, and St.18 have similarities in their floristic composition along with the target species and are thus grouped together in one cluster. Some stands were very peculiar to specific habitat type i.e. plain. It was found that St.12 and St.15 belongs to the category streams, St.5, St.6, St.13 and St.20 show similarity having the same type of habitat (i.e. field / farmland site), while St.7, St.8, St.16 and St.9 show similarity having (steep slopes). Plant communities have specific nutrient requirements and soil regime. Stands of the species were also classified into a cluster diagram based on their soil texture and nature. Soil being the dominant environmental variable has divided the plant stands into various branches of the cluster (Fig. 5). According to the figure, there are five types of soil texture such as rocky, muddy, loam, sandy and fine sand and loam. The Figure shows that St.4 and St.18 show similarity having the same type of soil with similar floristic composition (rocky), St.1, St.2, St.5, St.6, St.8, St.9, St.10, St.14, St.15, St.17 and St.20 show similarities having the same type of soil (muddy), St.12, St.16 and St.19 show similarity with soil type (loamy), St.4 and St.18 show similarity having the same type of soil (sandy) and St.3, St.7 and St.11 show similarity, having fine sand and loamy soil.

Table 3

Different reasons for survival of Punica granatum in Lower Dir District

\begin{tabular}{|c|c|c|c|c|c|c|c|c|}
\hline Reason for survival (Dir L) KP & FC (20-30) & FC (31-40) & FC (41-50) & FC (51-above) & $\sum \mathrm{Ui}$ & $\mathrm{N}$ & Use value (UV) & $\% U V$ \\
\hline Human inaccessibility & 4 & 2 & 6 & 9 & 21 & 114 & 0.18 & 18.42 \\
\hline Present on steep slopes & 3 & 3 & 2 & 7 & 15 & 114 & 0.13 & 13.15 \\
\hline Present on fertile soil & 0 & 6 & 4 & 5 & 15 & 114 & 0.13 & 13.15 \\
\hline Good water absorption & 2 & 0 & 5 & 8 & 15 & 114 & 0.13 & 13.15 \\
\hline Self-defence spines & 2 & 6 & 3 & 2 & 13 & 114 & 0.11 & 11.40 \\
\hline Strong secondary growth system & 2 & 3 & 4 & 3 & 12 & 114 & 0.10 & 10.52 \\
\hline Protection due to its medicinal value & 0 & 4 & 3 & 2 & 9 & 114 & 0.07 & 7.89 \\
\hline Resistance to drought conditions & 3 & 1 & 0 & 3 & 8 & 114 & 0.07 & 7.01 \\
\hline Rainfall frequency & 0 & 1 & 1 & 1 & 3 & 114 & 0.02 & 2.63 \\
\hline Protection from animals & 1 & 0 & 1 & 1 & 3 & 114 & 0.02 & 2.63 \\
\hline
\end{tabular}

Note: see Table 1.

Table 4

Reasons for decline of Punica granatum L. in Lower Dir. District

\begin{tabular}{|c|c|c|c|c|c|c|c|c|}
\hline Reason for decline (Dir L) KP & FC (20-30) & FC (31-40) & FC (41-50) & FC (51-above) & $\sum \mathrm{Ui}$ & $\mathrm{N}$ & Use value (UV) & \%UV \\
\hline Used as firewood & 2 & 7 & 8 & 5 & 22 & 129 & 0.170 & 17.05 \\
\hline Accessibility to humans & 5 & 4 & 6 & 5 & 20 & 129 & 0.155 & 15.50 \\
\hline Excessive use of fruits & 1 & 4 & 3 & 10 & 18 & 129 & 0.139 & 13.95 \\
\hline High palatability & 2 & 6 & 3 & 7 & 18 & 129 & 0.139 & 13.95 \\
\hline Soil erosion & 1 & 6 & 3 & 6 & 16 & 129 & 0.124 & 12.40 \\
\hline Overuse of the seeds & 3 & 0 & 3 & 6 & 12 & 129 & 0.093 & 9.30 \\
\hline Lack of protection & 2 & 2 & 2 & 2 & 8 & 129 & 0.062 & 6.20 \\
\hline Unsuitable growing areas & 2 & 1 & 2 & 2 & 7 & 129 & 0.054 & 5.42 \\
\hline Vulnerability & 2 & 2 & 0 & 1 & 5 & 129 & 0.038 & 3.87 \\
\hline Water logging and salinity & 1 & 1 & 0 & 1 & 3 & 129 & 0.023 & 2.32 \\
\hline
\end{tabular}

Note: see Table 1.

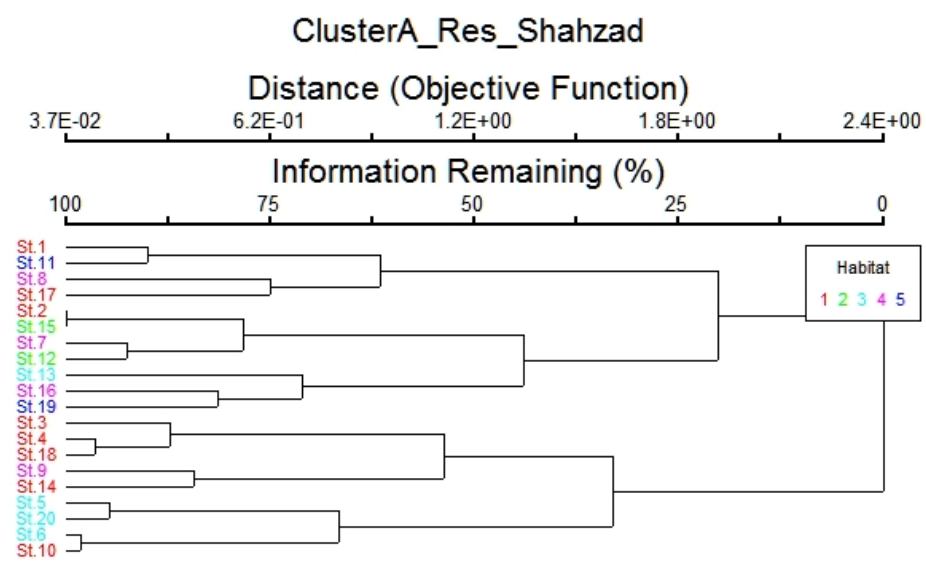

Fig. 4. Shows cluster analysis of habitat of the plant

Figure 5 shows that plant community and environmental variable (grazing) show similarity in various stands. According to the below figure St.4, St.6, St.7, St.9, St.10, St.12, St.14, St.15, St.18 and St.19 show absence of grazing while St.1, St.2, St.3, St.5, St.8, St.11, St.13, St.16, St.17 and St.20 show presence of grazing.

\section{Discussion}

Punica species belong to the Punicaceae family, mostly shrubs or small trees up to six m long and profusely branched from the base (Morton, 1987). The family Punicaceae includes only one genus and two species, extending throughout the Mediterranean region. The po- megranate tree is native from Iran to the Hiamalayas (Robert et al., 2002). The most important regions where $P$. granatum is found are Pakistan, Afghanistan, Egypt, China, Iran, Iraq, Bangladesh, India, Burma and Saudi Arabia. Wild pomegranates grow today in Central Asia from Iran and Turkmenistan to northern India (Rajaei and Parisa, 2015). In Pakistan, it grows at an altitude of 1000-2000 m, over the whole of the western and northern belt (South Waziristan, Khyber Pakhtunkhwa, Dir, Kurram, Chitral, Baluchistan). It also grows in Hazara regions; and has been found in Kashmir and in the Himalayan regions. (Kotamballi et al., 2003; Jurenka et al., 2008). Wild pomegranate is an endangered species which is found in areas which contain calcareous, alkaline, and sandy soil. 
Mostly, local people use it for the curing of different types of disease e.g. anti-cancer (Jeune et al., 2005), antioxidant (Gil et al., 2000). Its root bark is used for dysentery (Schubert et al., 1999). The fruit of pomegranate is used to treat microbial infection, diarrhoea and haemorrhage (Fuentes and Exposito et al., 1995). It is used as an antiseptic and for skin infections and injuries (Kotamballi et al., 2003; Juernka, 2008;
Das and Barman, 2012; Khan et al., 2013, 2014). Fresh leaves extract is used for dysentery, skin disease, checking of blood flow from nose and as eyewash. Fruits are as astringent, refrigerant, laxative, and used for blood purification. Seeds are dried and then used as a spice and condiment. Root and stem bark is anthelmintic, antipyretic, expectorant and used in mouth washes.

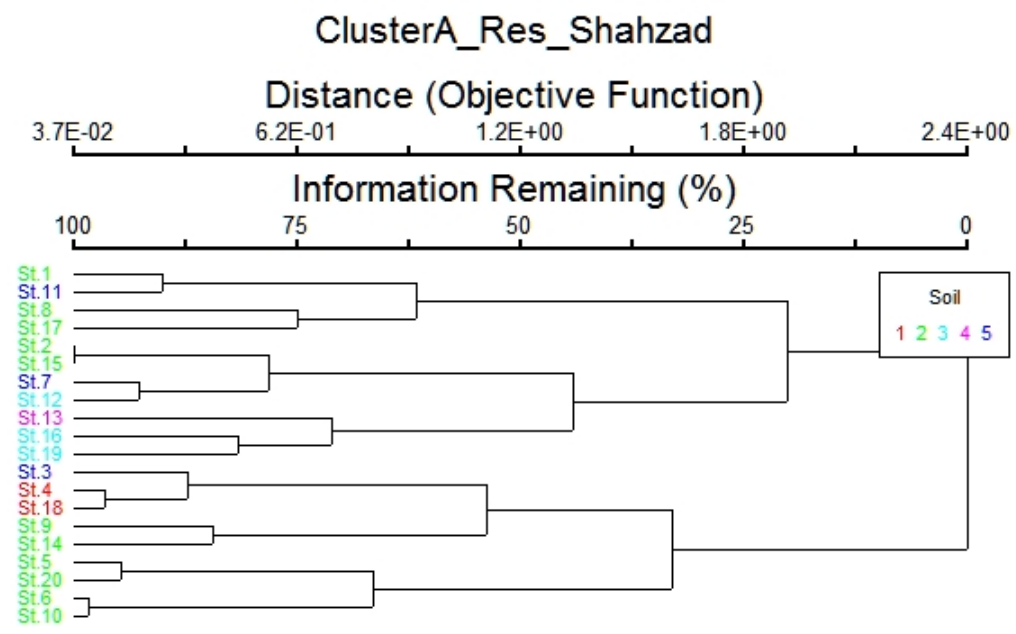

Fig. 5. Shows cluster analysis of soil types

Folk uses, various parts of the plant are used. 18.0\% of respondents used it for dry cough, $17.2 \%$ used it for urine irritation, $17.7 \%$ used it for stomach disease, 9.4\% used it for diarrhoea, $7.8 \%$ used it for blood purification, 6.3\% used it for bone pain, 6.3\% used it for chest pain, 4.7\% used it for skin irritation, $4.7 \%$ used it as a refrigerant, $3.9 \%$ used for dysentery, $3.1 \%$ as an anti-diabetic, $2.3 \%$ as an anthelmintic, $2.3 \%$ used it for throat infection, $2.3 \%$ used it as an expectorant and $1.8 \%$ used it as an astringent (Ali et al., 2017).

Fresh leaves are crushed and the extract is used for dysentery and skin diseases. The seeds are dried and used as a spice. The bark of stem and roots are dried and then converted to powder form, which is used as an expectorant, anthelmintic and antipyretic (Hassan et al., 2015). The fruit seeds are directly used (Nasrullah et al., 2012). The plant leaves are browsed by domestic stock. The tree branches are cut and used as firewood. Their wood is hard and durable, mostly used in making farm implements. From the root bark, a black ink is produced rich in tannins and useful in dyeing and leather (Nehofer et al., 2013; Ali et al., 2017).

Methods of use: $27.6 \%$ of respondents used it in powder form, $26.2 \%$ in powder form is mixed with water, $17.2 \%$ in powder form mixed with sugar, $10.3 \%$ as seed used as a food, $2.8 \%$ in powder form mixed with opium, $5.5 \%$ in powder form mixed with milk, $2.1 \%$ as seed mixed with vegetables, $1.4 \%$ by extraction of juice from seed, $2.8 \%$ in powder form mixed with other sweets and $4.1 \%$ used a small part of the fruit bark (Ali et al., 2017).

In some countries, paper or plastic bags or any other covers may be put over the fruits to protect them from borers, birds, bats and squirrels. Treatment with Carbendazin, is effective against fungal disease, carbendazin protects the fruits from damage (Morton, 1987).

Reasons for survival (Lower Dir) Khyber Pakhtunkhwa. 18.4\% of respondents claimed survival was due to human inaccessibility, 13.2\% due to presence on steep slopes, $13.2 \%$ due to presence on fertile soil, $13.2 \%$ due to good water absorption, $11.4 \%$ due to presence of protective spines, $10.5 \%$ due to their strong secondary growth system, $7.9 \%$ protection due to its medicinal value, $7.0 \%$ due to its resistance to drought condition, $7.0 \%$ due to rainfall frequency and $2.6 \%$ of respondents claimed its survival was due to protection from animals (Jurenka, 2008). Reasons for threat of extinction (Lower Dir) Khyber Pakhtunkhwa. $17.1 \%$ of respondents claimed the threat was due to use of plant stem and branches as firewood, $15.50 \%$ due to accessibility to humans, $13.9 \%$ due to excessive use of its fruits, $13.9 \%$ due to high palatability, $12.4 \%$ due to soil erosion, $9.3 \%$ due to overuse of the seeds, $6.2 \%$ due to lack of protection, $5.4 \%$ due to its presence in areas unsuitable for growth, $3.9 \%$ due to vulnerability and $2.3 \%$ due to water logging and salinity of the soil (Sadeghi and Kuhestani, 2014).

\section{Conclusions}

Finally, in the light of the findings of the present study, the following conclusions were drawn. We conclude that $P$. granatum is a commonly grown plant in Lower Dir district, found from areas in the plains to steep mountain slopes. We can also conclude that it is a highly medicinal plant and is in common domain of ethno-medicinal plants of the area. Around $18 \%$ people use it for dry cough, $27.6 \%$ use it in its powder form. According to the opinion of people, this plant has survived in the area due to difficult human access to some of its habitats. People also believe that the plant is endangered due to its excessive use and could soon vanish from the area.

The old age group interviewed showed better knowledge of the ethnoecology of the species. We personally believe that due to modernization of our society, people are not paying attention to preservation of this valuable ethnomedicinal knowledge. We also conclude that similar stands must have similar environmental conditions and should support similar floristic diversity.

We recommend that further studies on the impact of climate change on this plant should be carried out in the area and that the species should be given conservation priority for generations to come.

We sincerely thank all interviewees for taking part and sharing their knowledge. We are also grateful to the anonymous reviewers for all their useful suggestions and contributions.

\section{References}

Ahmad, B., Abbas, S. J., Hussain, F., Bashir, S., \& Ahmad, D. (2014). Study on Caralluma tuberculata nutritional composition and its importance as medicinal plant. Pakistan Journal of Botany, 46(5), 1677-1684.

Ali, K. (2015). A comparative assessment of climate change effect on some of the important tree species of Hindu-Kush Himalayas, using predictive modelling techniques. International Journal of Advanced Research, 3(5), 1230-1240.

Ali, K., Khan, N., Rahman, I. U., Ahmad, S., Khan, W., Ali, M., \& Sheday, A. A. (2017). Climate change: An evil or an opportunity-evidence from the HinduKush Mountain system of Pakistan. International Journal of Biosciences, 11(2), 99-105. 
Ali, K., Ullah, F., Khan, N., Rahman, I. U., Ullah, S., Khan, W., Ali, M., Uddin, N., \& Nisar, M. (2017). Ethnobotanical and ecological study of Myrtus communis (L.) in Bajaur agency (FATA) Khyber-Pakhtunkhwa, Pakistan. Journal of Biodiversity and Environmental Sciences, 11(1), 152-164.

Ali, M., Alam, M., Wadood, S. F., Khan, W., Uddin, N., Zaman, S. U., Nazir, N., Karim, N., Ali, Z., \& Nisar, M. (2017). Biochemical characterization of Pakistani Zea mays landraces growing in the remote areas of Khyber Pakhtunkhwa. International Journal of Biosciences, 11(3), 51-58.

Barman, S., \& Das, S. (2012). Antidiabetic and antihyperlipidemic effects of ethanolic extract of leaves of Punica granatum in alloxan-induced non-insulin-dependent diabetes mellitus albino rats. Indian Journal of Pharmacology, 44(2), 219-224.

BiBi, H., Afzal, M., Muhammad, A., Kamal, M., Sohail, Ullah, I., \& Khan, W. (2014). Morphological and anatomical studies on selected dicot xerophytes of district karak, Pakistan. American-Eurasian Journal of Agricultural and Environmental Science, 14(11), 1201-1212.

Chidambara Murthy, K. N., Jayaprakasha, G. K., \& Singh, R. P. (2002). Studies on antioxidant activity of pomegranate (Punica granatum) peel extract using in vivo models. Journal of Agricultural and Food Chemistry, 50(17), 4791-4795.

Fiallo, V. F., \& Montoya, A. E. (1995). Las encuestas etnobotanicas sobre plantas medicinales en Cuba [Enthobotanical survey of medicial plants in Cuba]. Rev. Jard. Bot. Nacion. Univ. Habana, 16, 77-145.

Gil, M. I., Tomás-Barberán, F. A., Hess-Pierce, B., Holcroft, D. M., \& Kader, A. A. (2000). Antioxidant activity of pomegranate juice and its relationship with phenolic composition and processing. Journal of Agricultural and Food Chemistry, 48(10), 4581-4589.

Jeune, M. A. L., Kumi-Diaka, J., \& Brown, J. (2005). Anticancer activities of pomegranate extracts and genistein in human breast cancer cells. Journal of Medicinal Food, 8(4), 469-475.

Jurenka, J. (2008). Therapeutic applications of pomegranate (Punica granatum L.): A review. Alternative Medicine Review, 13(2), 128.
Khan, N., Ahmed, M., Wahab, M., \& Hussain, S. S. (2010). Studies along an altitudinal gradient in Monotheca buxifolia (Falc.) ad, forest, District Lower Dir, Pakistan. Pakistan Journal of Botany, 42(5), 3029-3038.

Khan, N., Ali, K., \& Shaukat, S. (2014). Phytosociology, structure and dynamics of Pinus roxburghii associations from Northern Pakistan. Journal of Forestry Research, 25(3), 511-521.

Khan, N., Shaukat, S. S., Ahmed, M., \& Siddiqui, M. F. (2013). Vegetation-environment relationships in the forests of Chitral district Hindukush range of Pakistan. Joumal of Forestry Research, 24(2), 205-216.

Lucas, G., \& Synge, H. (compilers) (1978). IUCN plant red data book. Unwin Bros., Ltd., UK.

Neuhofer, H., \& Witte, L., \& Gorunovic, M., \& Czygan, F.-C. (1993). Alkaloids in the bark of Punica granatum L. (Pomegranate) from Yugoslavia. Pharmazie, 48, 389-391.

Nisar, M., \& Ali, Z. (2012). Ethnobotanical wealth of Jandool Valley, Dir Lower, Khyber Pakhtunkhwa (KPK), Pakistan. International Journal of Phytomedicine, 4(3), 351-354.

Rajaei, H., \& Yazdanpanah, P. (2015). Buds and leaves in pomegranate (Punica granatum L.): Phenology in relation to structure and development. Flora Morphology, Distribution, Functional Ecology of Plants, 214, 61-69.

Rawat, J. M. S., \& Tomar, Y. K., \& Rawat, V. (2017). Effect of stratification on seed germination and seedling performance of wild pomegranate. Journal of American Science, 6(5), 97-99.

Sadeghi, Z., \& Kuhestani, K. (2014). Ethnobotany of date palm (Phoenix dactylifera) in Baluch tribe of Saravan region, Baluchistan, Iran. Journal of Agricultural Technology, 10(6), 1571-1585.

Schubert, S. Y., Lansky, E. P., \& Neeman, I. (1999). Antioxidant and eicosanoid enzyme inhibition properties of pomegranate seed oil and fermented juice flavonoids. Journal of Ethnopharmacology, 66(1), 11-17. 